\title{
Chronic Diseases, Health Status and Health Service Utilization among Koreans
}

\author{
Ju Moon Park* \\ Department of Urban Policy and Administration, Incheon National University, Incheon, South Korea \\ Email: ${ }^{*}$ jumoonpark@incheon.ac.kr
}

Received 16 July 2014; revised 2 September 2014; accepted 17 September 2014

Copyright (C) 2014 by author and Scientific Research Publishing Inc.

This work is licensed under the Creative Commons Attribution International License (CC BY).

http://creativecommons.org/licenses/by/4.0/

(c) (i) Open Access

\begin{abstract}
This study described the self-reported chronic diseases and health status and examined the factors that are associated with effective health service utilization. Descriptive and logistic regression analysis was performed to determine the factors significantly associated with self-rated health, in-patient and out-patient utilization. Self-rated health status was ranked lower among rural residents, lower-income families, married persons, and those with chronic diseases. Chronic diseases such as hypertension, arthritis, melancholy, and diabetes were common and they are associated with poor health of Koreans. The presence of chronic diseases was significant in predicting the likelihood of poor health while socio-economic factors, rather than health-related need factors, had more predictive power of the use of health services. This study provides a unique contribution to the knowledge base of the Korean population. The study findings show that Koreans in poor health status were married, living in rural areas, having chronic diseases and lower income, with a high likelihood of health care utilization among employed individuals, which could significantly help in the public health policy required to address this issue.
\end{abstract}

\section{Keywords}

Health Services, Utilization, Chronic Diseases, Health Status, Koreans, Health Policy

\section{Introduction}

A World Health Organization (WHO) study projected an increase of global deaths by $17 \%$ in the period 2005-2015, meaning that of the 64 million estimated deaths in 2015, 41 million, or 64\%, will die of a chronic disease [1]. Most of them were due to cardiovascular disorders and diabetes (32\%), cancers (13\%), and chronic respiratory diseases (7\%) [2]. Korea is no exception. According to Korea Institute for Health and Social Affairs,

Corresponding author. 
54.3\% of Koreans over 20 years of age have a chronic disease [3]. For Korea, diabetes mortality was two or three times as much as the Organization for Economic Cooperation and Development (OECD) average. As chronic diseases emerge as a serious threat to Korean health, their health burden is likely to worsen.

Self-rated or perceived health status has widely gained recognition as an important client-based health outcome indicator [4]. Health service utilization is also of interest, because of its relation to health status. Health status and health services utilization are important determinants of health, and have a particular relevance for public health [5]. An individual's decision to utilize health care results from a complex interaction of multiple factors linking to one's self-perceived health and the availability of health care [6]. Previous studies show that personal attributes which may predispose individuals to seek care, need for services as evidenced by illness and enabling factors such as financial capability to pay for health care, ability to get to places where services are offered and knowledge about the service network in the community are associated with health care utilization [7].

Even though many different health status indicators have been developed [8], choosing an appropriate health status variable is, in particular, crucial to obtaining meaningful results [9]. The variable used to measure health should sensitively reflect those dimensions of health (or morbidity) of special concern for the purposes of the analysis [10]. For this study, I will select one of the most widely used health status variables, the self-rated health status and examine that chronic diseases associated with health status of Koreans. I will also explore which indices are important for health in Korea and the significant predictors that are associated with health service utilization and then I will suggest appropriate ways to improve the health condition of the population.

This type of study and its findings are important. First, it contributes to provide important information on the self-reported chronic diseases, health status and predictors of health and health service utilization among Koreans. Second, there are few articles that address this issue in Korea and some variables, such as "health status", have not yet been adequately explored. To my knowledge, they are mainly focused on the determinants associated with health service utilization and equity of access to care in Korea [11]-[14]. Finally, it will assist in the design of interventions to increase the access of poor groups to the health care system.

The aim of this study is to (a) describe the self-reported chronic diseases and health status and (b) examine the factors that are associated with health and health services utilization.

\section{Methods}

\subsection{Sample}

Data comes from the Korea National Health and Nutrition Examination Survey (KNHANES), which was conducted in 2010. The survey collected data via household interviews and by direct standardized physical examinations conducted in specially equipped mobile examination centers. A stratified, multistage probability sampling design with proportional allocation based on the National Census Registry was used for the selection of household units. In the 2010 KNHANES, there were 192 primary sampling units, each of which contained 20 households. 20 households from each primary sampling unit were sampled using a systemic sampling method. Finally, the individuals in 3840 households were sampled and participated in health interviews and health examination surveys. This study focuses on cross-sectional analyses, using the 2010 Korea National Health and Nutrition Examination Survey data. The sample for the 2010 KNHANES consists of a total of 8958 aged 1 year or older.

For the analysis, the sample was weighted to reflect the population of the nation. To account for design effects created by stratified multistage sampling, Weights and strata were used in the estimation.

\subsection{Measures}

The demographic and socioeconomic measures included age, gender, residence, marital status, education, income, and working status. The health measures of health status included questions on whether the subject considered his or her health to be very good, good, fair, poor or very poor, and whether a chronic condition had been a problem during the last 24 months (hypertension, stroke, heart disease, arthritis, tuberculosis, asthma, thyroid/other glad problems, diabetes, liver disease, skin problems, melancholy, and cancer). The measures of health services utilization were based on whether the sample person had been to see a physician during the past 14 days preceding the interview; and whether the respondents had been a patient in the hospital within the preceding 12 months. The responses of services utilized were coded as either "yes" or "no", i.e., 1 or 0 . It was 
shown that $10.2 \%$ of the respondents used hospital services and $34.4 \%$ physician services.

There was no information missing for any of the demographic, socioeconomic and need variables, except for the following variables (for which the number of cases is noted in parentheses): education (8801), marital status (5777), family income (8824), working status (6899), and health status (8370).

For the logistic regression analysis, the study variables were recoded so as to indicate dichotomies. The first category for a variable was coded 1 and the reference category for it (after "vs") was coded 0.

\subsection{Analysis}

Descriptive statistics such as mean, standard deviation (SD), frequency and percentage were used to analyze the demographic and socio-economic characteristics of the sample. Associations of self-reported chronic diseases, health status and health care utilization were assessed by Pearson chi-square tests. Logistic regression analysis was then used to determine the factors significantly associated with self-rated health, in-patient and out-patient utilization. A logistic regression model is distinguished from other regression model by the fact that the outcome variable is binary or dichotomous, e.g., the presence or absence of health care utilization (HCU). HCU $(y=1)$ : health care utilization is present: HCU ( $\mathrm{y}=0)$ : health care utilization is absent. The logistic function is used to model the probability of health care use during the past fifteen days or the past twelve months as a function of various independent variables. Under this logistic function, the probability that an individual uses health care services depends on the independent variables, $X_{1}, X_{2}, X_{3}, \cdots, X_{n}$ according to the relation,

$P(X)=1 / 1+\mathrm{e}^{-\left(\beta_{0}+\sum \beta_{i} X_{i}\right)}$ where, $\beta_{0}$ and $\beta_{i}$ are respectively the unknown parameters of the variable [15]. The independent variables were age, gender, education, residence, marital status, income, and working status. To avoid over-fitting the model, only those variables found to be significant on bivariate analysis were included in the final regression model. All tests were conducted at the $5 \%$ level of significance. The percentage and the odds ratio (OR) were reported with a 95\% confidence interval (CI).

\section{Results}

\subsection{Socio-Economic Characteristics}

Survey respondents had a higher percentage of urban residence, a higher percentage with no formal education or primary education, a higher percentage with an income of 4 million won (USD $=3500$ ) or less and a higher percentage of those who were younger, female, married, and employed (Table 1). The average age of the respondents was $39.3 \pm 22.7$ years old. $54.5 \%$ of the respondents were female. $40.9 \%$ of the respondents had no formal or a primary education, $36.4 \%$ had a secondary education and $22.7 \%$ had a tertiary education. $64.6 \%$ of the respondents were married. $77.8 \%$ of the respondents resided in urban area. $65.6 \%$ of the respondents had a monthly family income of $\leq 4$ million won and $34.4 \%$ earned $>4$ million won. The monthly average income respondents or their family members earned was 4,293,000 $\pm 8,222,000$ won. 57.0 percent of the respondents were employed.

\subsection{Self-Rated Health and Chronic Diseases}

Table 2 presents the respondents' reports of self-rated health and chronic diseases. Residents with poor or very poor self-rated health were $16.9 \%$ (95\% confidence interval: $16.1 \%-17.7 \%$ ). $9.6 \%$ of the women and $7.3 \%$ of the men rated their health as poor or very poor (Table 2). The prevalence of self-reported chronic diseases was $37.5 \%$ (95\% confidence interval: 36.5\% - 38.5\%). The prevalence of chronic diseases reported by women was $19.5 \%$ and men were $18.0 \%$. Self-reported prevalence of arthritis, hypertension, melancholy, and diabetes were $15.9 \%, 15.3 \%, 12.5 \%$, and $8.3 \%$, respectively. Other chronic diseases reported included tuberculosis (5.7\%), skin problems (4.5\%), asthma (4.7\%), thyroid/other gland problems (4.1\%), heart disease (2.9\%), stroke (1.8\%), cancer $(1.8 \%)$, and liver problems (1.6\%). The most common chronic diseases reported by women and men were hypertension, arthritis, melancholy, and diabetes (Table 2). The prevalence of self-reported chronic diseases increased progressively with age and education level, and was higher among females, those who were married or unemployed, urban residents, respondents with a monthly family income of $\leq 4,000,000$ won, and those who assessed their health poor or very poor (Table 3).

Multivariate logistic regression was performed to identify the significant predictors of the resident's self-rated 
Table 1. Demographic and other characteristics of the sample $(\mathrm{N}=8958)$.

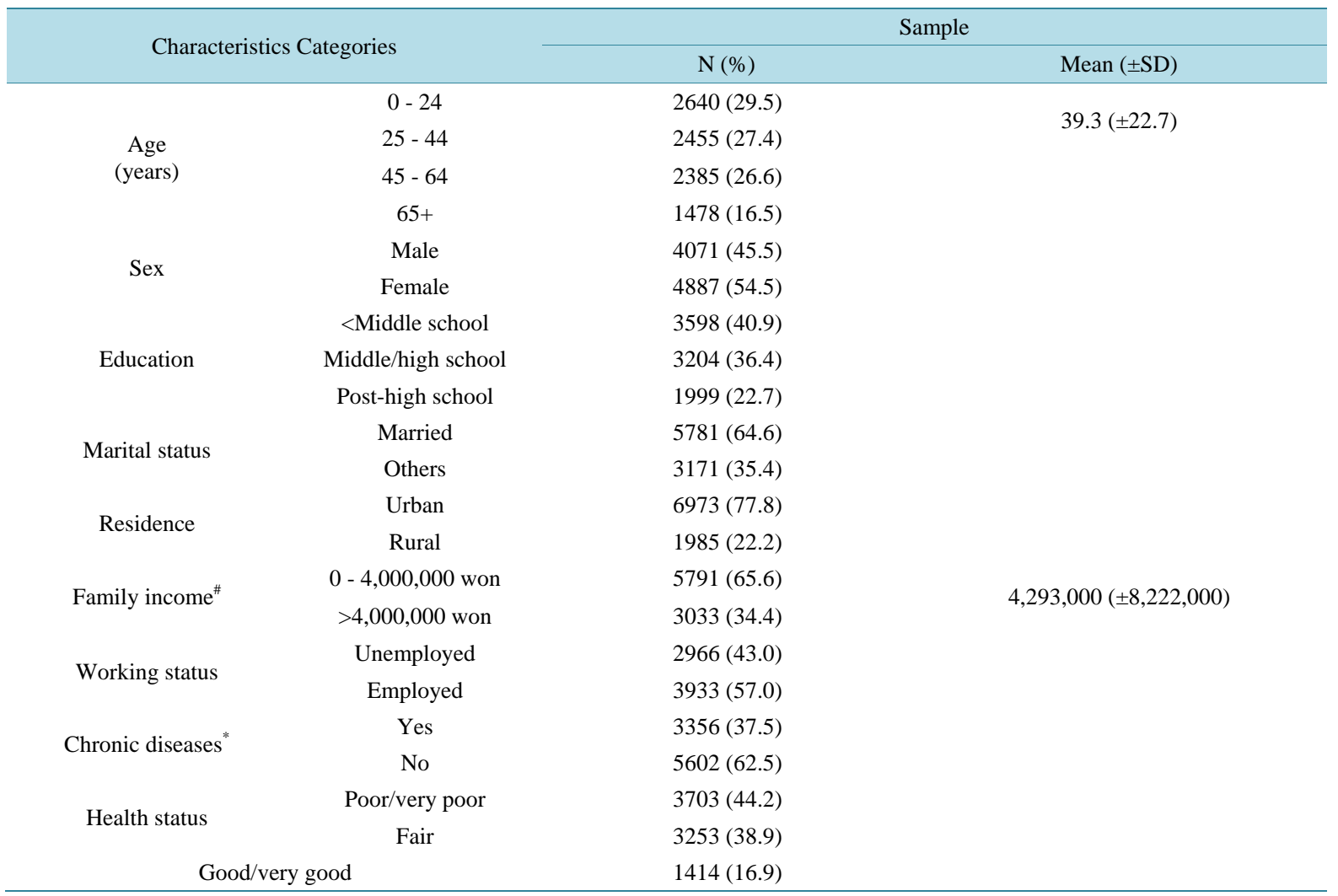

"Refers to hypertension, arthritis, melancholy, diabetes, Tuberculosis, skin problems, asthma, thyroid/other gland problems, heart disease, cancer, liver problems, and stroke. "Korean monetary unit. Note: The number of cases on which the estimates are based on is 8958, except for the following variables (for which the number of case isnoted in parentheses): education (8801), marital status (5777), family income (8824), working status (6899), health status (8370).

Table 2. Health status and self-reported chronic diseases of the sample ( $\mathrm{N}=8958)$.

\begin{tabular}{|c|c|c|c|c|}
\hline \multirow{2}{*}{ Characteristics } & \multicolumn{3}{|c|}{$\%$} & \multirow{2}{*}{ p-value } \\
\hline & Females & Males & Both & \\
\hline Health status & & & & $<0.01$ \\
\hline Poor/very poor & 9.6 & 7.3 & 16.9 & \\
\hline Fai & 21.2 & 17.7 & 38.8 & \\
\hline Good/very good & 24.0 & 20.2 & 44.2 & \\
\hline Chronic diseases & & & & $<0.01$ \\
\hline Hypertension & 12.5 & 10.0 & 12.5 & \\
\hline Stroke & 1.2 & 0.6 & 1.8 & \\
\hline Heart disease & 1.7 & 1.2 & 2.9 & \\
\hline Arthritis & 9.2 & 6.7 & 15.9 & \\
\hline Tuberculosis & 2.8 & 2.9 & 5.7 & \\
\hline Asthma & 2.5 & 2.2 & 4.7 & \\
\hline Thyroid & 2.4 & 1.7 & 4.1 & \\
\hline Diabetes & 4.5 & 3.8 & 8.3 & \\
\hline Liver problems & 1.1 & 0.5 & 1.6 & \\
\hline Skin problems & 2.6 & 2.0 & 4.5 & \\
\hline Melancholy & 8.9 & 6.4 & 15.3 & \\
\hline $\mathrm{Ca}$ & 1.0 & 0.8 & 1.8 & \\
\hline
\end{tabular}


Table 3. Demographic and other characteristics of the sample $(\mathrm{N}=8958)$.

\begin{tabular}{|c|c|c|c|c|c|}
\hline \multirow{2}{*}{\multicolumn{2}{|c|}{$\begin{array}{l}\text { Characteristics } \\
\text { Categories }\end{array}$}} & \multicolumn{4}{|c|}{$\%$} \\
\hline & & Chronic diseases & Physician visit & Hospitalization & Poor health \\
\hline \multirow{4}{*}{$\begin{array}{l}\text { Age } \\
\text { (years) }\end{array}$} & $0-24$ & 35.2 & 31.3 & 6.9 & 16.7 \\
\hline & $25-44$ & 38.0 & 26.0 & 10.8 & 16.1 \\
\hline & $45-64$ & 38.2 & 36.7 & 10.5 & 17.3 \\
\hline & $65+$ & 39.2 & 50.4 & 15.0 & 17.8 \\
\hline \multirow{2}{*}{ Sex } & Male & 38.8 & 38.0 & 11.1 & 17.5 \\
\hline & Female & 35.9 & 30.2 & 9.2 & 16.2 \\
\hline \multirow{3}{*}{ Education } & $<$ Middle school & 36.6 & 41.6 & 10.5 & 17.7 \\
\hline & Middle/high school & 37.9 & 29.5 & 10.2 & 16.3 \\
\hline & Post-high school & 39.1 & 29.4 & 9.8 & 16.7 \\
\hline \multirow{2}{*}{ Marital status } & Married & 53.4 & 34.5 & 10.3 & 22.1 \\
\hline & Others & 8.5 & 34.3 & 10.2 & 7.5 \\
\hline \multirow{2}{*}{ Residence } & Rural & 40.3 & 36.9 & 13.1 & 21.0 \\
\hline & Urban & 36.7 & 33.8 & 9.5 & 15.7 \\
\hline \multirow{2}{*}{ Family income ${ }^{\#}$} & 0 - 4,000,000 won & 41.4 & 34.3 & 10.0 & 19.9 \\
\hline & $>4,000,000$ won & 30.3 & 34.9 & 10.8 & 11.5 \\
\hline \multirow{2}{*}{ Working status } & Unemployed & 38.2 & 31.0 & 9.7 & 17.4 \\
\hline & Employed & 39.0 & 38.2 & 12.9 & 16.4 \\
\hline \multirow{2}{*}{ Chronic diseases $^{*}$} & Yes & - & 34.1 & 10.4 & 30.2 \\
\hline & No & - & 34.6 & 10.1 & 8.2 \\
\hline \multirow{2}{*}{ Health status } & Poor/very poor & 33.7 & 34.9 & 10.4 & - \\
\hline & Fair/Good/very good & 71.6 & 33.6 & 10.1 & - \\
\hline
\end{tabular}

*Refers to hypertension, arthritis, melancholy, diabetes, Tuberculosis, skin problems, asthma, thyroid/other gland problems, heart disease, cancer, liver problems, and stroke. "Korean monetary unit. Note: The number of cases on which the estimates are based on is 8958, except for the following variables (for which the number of case is noted in parentheses): education (8801), marital status (5777), family income (8824), working status (6899), health status (8370).

health. Self-rated health was lower among those who were married, rural residents, those who had chronic diseases, and respondents with a monthly family income of $\leq 4,000,000$ won. Marital status, residence, income, and the presence of chronic diseases significantly predicted the respondent's self-rated health. Respondents with chronic diseases were 4 times more likely to report self-rated poor health (odds ratio: 4.78, 95\% CI: 3.91 - 5.86) than residents with no chronic disease (Table 4).

\subsection{Predictors of Health Service Utilization}

The odds ratio for physician and inpatient hospital utilization, simultaneously adjusted for multiple independent variables, are presented in Table 4. Those who were less likely to have used physician services included those who were 45 years or less, women, those who had no education or a primary education, and unemployed persons. The demo-economic variables such as age, sex, education, and working status were important determinants of physician utilization among Koreans. Those who were less likely to have used inpatient hospital services included women, rural residents, and unemployed persons. Sex, residence, and working status were important determinants of hospital service utilization among Koreans. As presented in Table 4, all of the regression models were significant $(\mathrm{p}<0.0001)$ in predicting Koran physicians, inpatient hospital services, and poor health status.

\section{Discussion}

The findings of this study provide important information on the health status and predictors of health service utilization among Koreans. Self-rated health status was ranked lower among rural residents, lower-income families, married persons, and those with chronic diseases. Although there were no statistically significant differences in 
Table 4. Multivariate logistic regression analysis of predictors of health services utilization for Koreans, weighted.

\begin{tabular}{|c|c|c|c|c|c|c|}
\hline \multirow{2}{*}{ Determinants } & \multicolumn{2}{|c|}{ Poor health } & \multicolumn{2}{|c|}{ Physician visit } & \multicolumn{2}{|c|}{ Hospitalization } \\
\hline & $\mathrm{OR}^{\mathrm{a}}$ & 95\% CI & OR & $95 \%$ CI & OR & $95 \%$ CI \\
\hline Age (years) $45+$ vs. 0 - 44 & 1.00 & $0.81-1.21$ & $0.52^{* *}$ & $0.45-0.60$ & 0.89 & $0.73-1.11$ \\
\hline Sex Female vs. Male & 1.11 & $0.92-1.33$ & $0.62^{* *}$ & $0.54-0.71$ & $0.75^{* *}$ & $0.61-0.92$ \\
\hline Education High-school graduate+ vs. $\leq$ Middle-school graduate & 1.17 & $0.95-1.44$ & $1.21^{*}$ & $1.04-1.41$ & 1.00 & $0.81-1.24$ \\
\hline Marital status Married vs. Unmarried/divorced & $1.61^{* *}$ & $1.26-2.05$ & 1.08 & $0.93-1.26$ & 0.95 & $0.75-1.19$ \\
\hline Residence Rural vs. Urban & $1.45^{* *}$ & $1.19-177$ & 0.95 & $0.81-1.12$ & $0.75^{*}$ & $0.60-0.94$ \\
\hline Family income Less than $4,000,000$ won vs. $4,000,000$ won+ & $1.83^{* *}$ & $1.49-2.24$ & 1.06 & $0.92-1.22$ & 1.09 & $0.89-1.34$ \\
\hline Working status Employ vs. Unemployed & 1.08 & $0.90-1.30$ & $1.20^{* *}$ & $1.05-1.39$ & $1.31^{* *}$ & $1.07-1.60$ \\
\hline Chronic diseases Yes vs. No & $4.78^{* *}$ & $3.91-5.86$ & 1.03 & $0.89-1.19$ & 0.94 & $0.76-1.18$ \\
\hline Model chi-square & \multicolumn{2}{|c|}{4606528.8} & \multicolumn{2}{|c|}{1927897.5} & \multicolumn{2}{|c|}{262608.5} \\
\hline Degree of freedom & \multicolumn{2}{|c|}{8} & \multicolumn{2}{|c|}{8} & \multicolumn{2}{|c|}{8} \\
\hline Significance & \multicolumn{2}{|c|}{$<0.0001$} & \multicolumn{2}{|c|}{$<0.0001$} & \multicolumn{2}{|c|}{$<0.0001$} \\
\hline
\end{tabular}

${ }^{*} \mathrm{p}<0.05 .{ }^{* *} \mathrm{p}<0.01$. Note: All other statistics not significant at $\mathrm{p}<0.05$. OR is an abbreviation for odds ratio.

self-rated health among men and women, important geographic differences were observed. A higher rate of rural residents in this study reported poor or very poor health than urban residents. The fact that $21 \%$ of rural residents reported poor or very poor health status is a concern, especially since those with chronic diseases were 4 times more likely to report self-rated poor health than residents with no chronic disease. Poor health status may be associated with a number of factors. More women than men reside in rural areas. Rural women have more chronic diseases compared to rural men [16]. Women in rural areas are particularly affected and their special needs are often ignored by a health planner [17]. Furthermore, women who grew up in traditional patriarchal families may have been socialized to place the needs of other family members before their own, which may have hindered them from seeking medical services [18]. Being married indicates worse self-reported health than a single or divorced/widowed person, similar to that reported in another study [19]. Socio-economic factors seem to be significant in explaining health status. As found in most studies, having a lower income is associated with self-rated poor health than having a higher income.

An interesting finding in this study is the fact that people living in urban areas have significant higher utilization of specialist services than people living in rural areas. This may be related to the geographic mal-distribution of providers that may be reflected in the lower utilization of specialists in rural areas [13]. In Korea, with the government's "laissez-faire" policy for the private medical sector, more than $90 \%$ of physicians and hospital beds are concentrated in urban areas. Meanwhile, the provision of private medical facilities has not been subject to stringent legislation [14]. Regarding socio-economic factors, education is insignificant for doctor visits, but significant for visits to specialists. People with higher levels of education are more likely to use specialist services than their counterparts. Compared with those who are not in the labor force, individuals who reported being in the labor force are more likely to consult a doctor and be hospitalized. From this study, working status emerges as a significant predictor of utilization of physicians and specialists. Age is insignificant for outpatient utilization, but significant for inpatient utilization. Sex is generally significant for both outpatient and inpatient utilization, As a result, age, sex, education, and working status predicted physician utilization and sex, residence, and working status were important predictors of hospital service utilization. However, regarding chronic diseases, this study found no link between chronic diseases and health service utilization. This may be due to the fact that Koreans with chronic diseases utilize more long-term care services since long-term care insurance provides for care services that go beyond acute medical needs [20].

These findings are subject to the limitations of secondary data. First, the analysis model, as used in this study, was limited to the data collected by the Korea National Health and Nutrition Examination Survey in 2010. There is the difficulty that arises as the result of using the model with the secondary data, e.g., as for the study design, none of the established association can be inferred as a cause-effect relation. Second, the data relies on subjective measures of health status and does not include objective measures of chronic diseases. Third, this survey does not provide information on subject refusals and/or non-contacted subjects, and thus, even though the participant rate was $77.5 \%$, the response rate could not be calculated. Nevertheless, this study does provide the most reliable up-to-date information on the prevalence of chronic diseases and on their relationships with health status 
in the Korean population.

\section{Conclusion}

The results of this study indicate that chronic diseases such as hypertension, arthritis, melancholy, and diabetes are common and that they are associated with poor health of Koreans. Without vigorous efforts to prevent and treat chronic diseases, the socioeconomic burden is predicted to be enormous. This highlights the importance to support or establish chronic care centers and ease health care availability for the persons with poor health status (e.g. rural residents and low-income families) in order to properly manage subsequent poor health. Lastly, it is important to note that socio-economic factors, rather than health-related factors, have more predictive power of the use of health services. This finding is inconsistent with previous studies [13] [14], showing the opposite result. I observed a $20 \%$ - 30\% higher likelihood of health care utilization among individuals who have working status than those who have never had. Areas of work bring diverse people together and as they intermingle, information exchange on various aspects such as health and education wide-spreads [7], thus impact one's health attitude and consequently utilization. Helping Koreans obtain working status will thus facilitate the use of health services among Koreans. This study provides a unique contribution to the knowledge base of the Korean population. The study findings show that Koreans in poor health status were married, living in rural areas, having chronic diseases and low income, with a high likelihood of health care utilization among employed individuals, which could significantly help in the public health policy required to address this issue.

\section{Acknowledgements}

This work was supported by the Incheon National University Research Grant in 2014. A special word of thanks goes to Korea Centers for Disease Control and Prevention which provided the data for this study.

\section{References}

[1] World Health Organization (2005) Preventing Chronic Diseases: A Vital Investment. World Health Organization, Geneva.

[2] Abegunde, D.O., Mathers, C.D., Adam, T., Oregon, M. and Strong, K. (2007) The Burden and Costs of Chronic Diseases in Low-Income and Middle-Income Countries. The Lancet, 370, 1929-1938.

[3] Yang, B.G. (2012) Chronic Disease Control for Improving Health. Health Welfare Forum, Korea Institute for Health Social Affairs, Seoul, 193.

[4] Rohrer, J.E., Arif, A., Denison, A., Young, R. and Adamson, S. (2007) Overall Self-Rated Health as an Outcome Indicator in Primary Care. Journal of Evaluation in Clinical Practice, 13, 882-888. http://dx.doi.org/10.1111/j.1365-2753.2006.00692.x

[5] Chakraborty, N., Islam, M.A., Chowdhury, R.I., Bari, W. and Akhter, H.H. (2003) Determinants of the Use of Maternal Health Services in Rural Bangladesh. Health Promotion International, 18, 327-337. http://dx.doi.org/10.1093/heapro/dag414

[6] Fernandez-Olano, C., Hidalgo, J.D.L., Cerda-Diaz, R., Requena-Gallego, M., Sanchez-Castaoo, C., Urbistondo-Cascales, L. and Otero-Puime, A. (2006) Factors Associated with Health Care Utilization by the Elderly in a Public Health Care System. Health Policy, 75, 131-139. http://dx.doi.org/10.1016/j.healthpol.2005.02.005

[7] Wan, T.T.H. and Odell, B.G. (1981) Factors Affecting the Use, Social and Health Services among the Elderly. Aging and Society, 1, 95-115. http://dx.doi.org/10.1017/S0144686X81000068

[8] Brook, R.H., Ware, J.E., Davies-Avery, A., Stewart, A.L., Donald, C.A., Rogers, W.H., Williams, K.N. and Johnston, S.A. (1979) Overview of Adult Health Status Measures Fielded in Rand's Health Insurance Study. Medical Care, 17, iii-X, 1-131.

[9] Ware, J.E., Brook, R.H., Davies, A.R. and Lohr, K.N. (1981) Choosing Measures of Health Status for Individuals in General Populations. American Journal of Public Health, 71, 620-625. http://dx.doi.org/10.2105/AJPH.71.6.620

[10] Pope, G.C. (1988) Medical Condition, Health Status, and Health Services Utilization. Health Services Research, 22, 857-877.

[11] Cho, S. (1989) The Emergence of a Health Insurance System in a Developing Country: The Case of South Korea. Journal of Health and Social Behavior, 30, 467-471. http://dx.doi.org/10.2307/2136993

[12] Park, J.M. (1994) The Determinants of Physician and Pharmacist Utilization and Equity of Access under Korean Universal Health Insurance. PhD Thesis, University of Texas, Houston. 
[13] Park, J.M. (2012) Equity of Access to Primary Care among Older Adults in Incheon, South Korea. Asia-Pacific Journal of Public Health, 24, 953-960. http://dx.doi.org/10.1177/1010539511409392

[14] Park, J.M. (2012) Equity of Access under Korean Universal Health Insurance. Asia-Pacific Journal of Public Health. http://dx.doi.org/10.11177/101053912446961

[15] Hosmer, D. and Lemeshow, S. (1989) Applied Logistic Regression. John Wiley and Sons, Hoboken.

[16] Korean Statistical Office (2011) Report on the 2010 Agriculture and Fisheries Corporation Survey. Korean Statistical Office, Daejon.

[17] Korean Ministry of Health and Welfare (2011) National Health and Nutrition Survey Data Set. Korea Institute for Health and Social Affairs, Seoul.

[18] Myke, P. (1991) Women and Health. Zed Books, London.

[19] Homma-True, R. (1997) Asian American Elders. In: Le, Ed., Working with Asian Americans: A Guide for Clinicians, Guilford Press, New York, 420-427.

[20] Jenssen, S. (2006) Health Status and Utilization of Physicians. Paper presented at the 8th Nordic Seminar on Microsimulation Models, Oslo, 7-9 June 2006. 
Scientific Research Publishing (SCIRP) is one of the largest Open Access journal publishers. It is currently publishing more than 200 open access, online, peer-reviewed journals covering a wide range of academic disciplines. SCIRP serves the worldwide academic communities and contributes to the progress and application of science with its publication.

Other selected journals from SCIRP are listed as below. Submit your manuscript to us via either submit@scirp.org or Online Submission Portal.
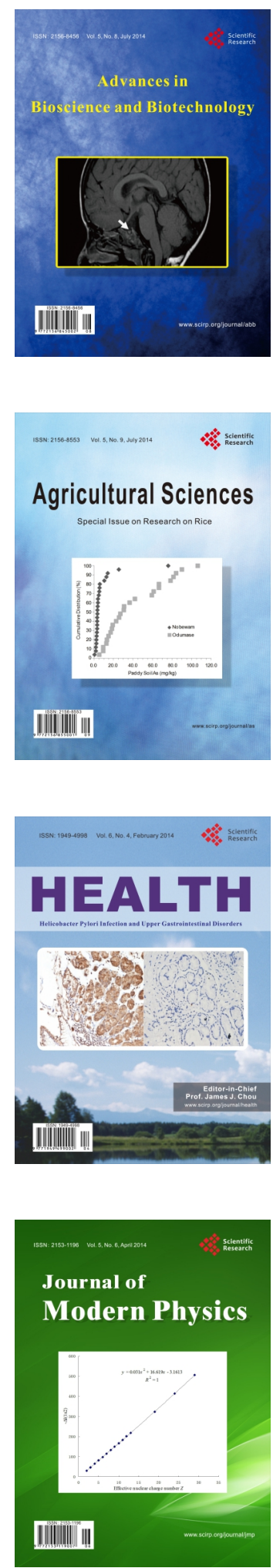
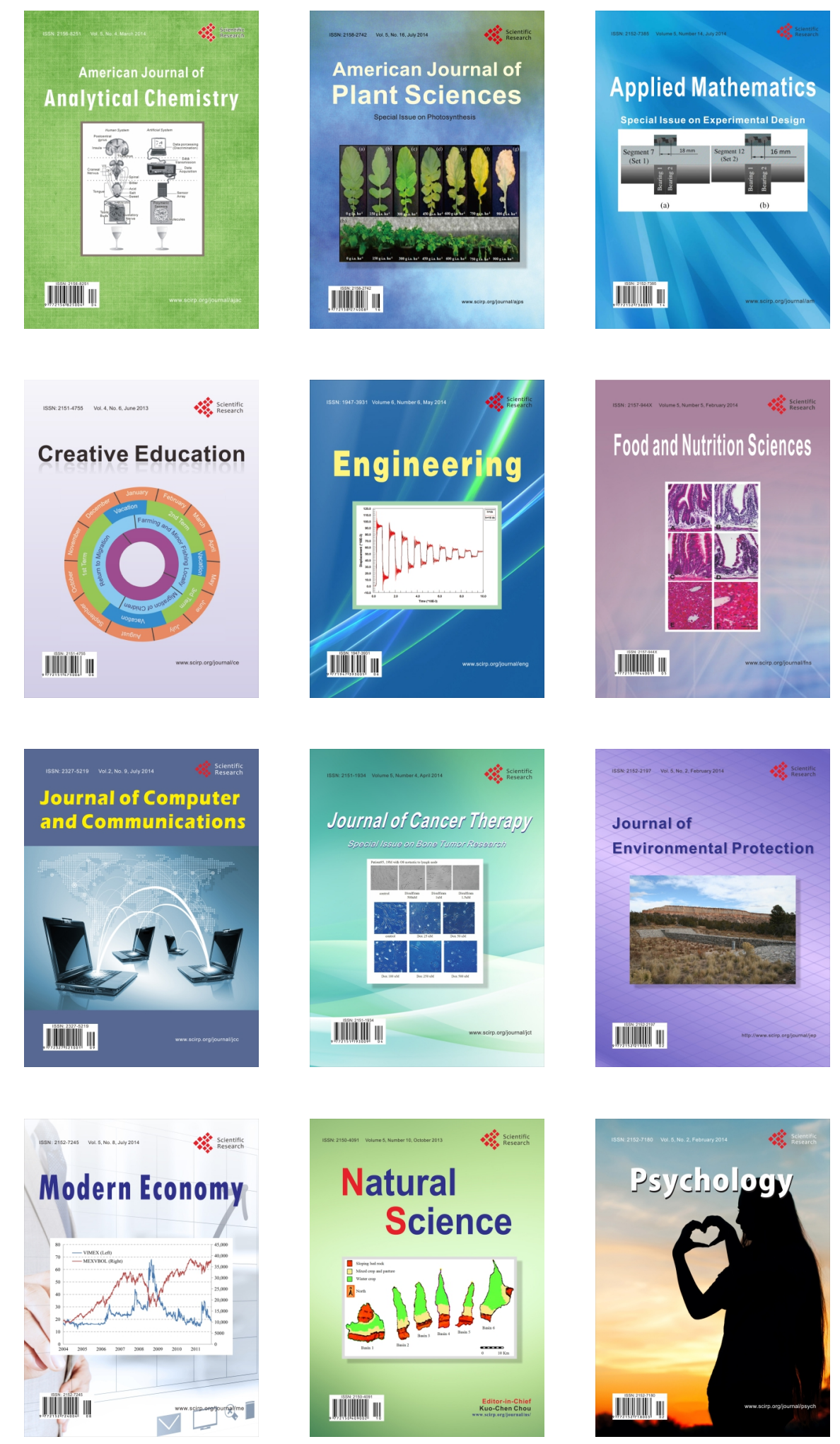